Proc. Indian Acad. Sci. (Chem. Sci.), Vol. 105, No. 6, December 1993, pp. 583-589.

(C) Printed in India.

\title{
Light induced cycloadditions of captodative alkenes
}

\author{
D DÖPP*, J BREDEHORN, A W ERIAN ${ }^{\dagger}$, A JUNG, \\ H LANFERMANN, H R MEMARIAN $\$$, B MÜHLBACHER \\ and $M$ PIES
}

Fachgebiet Organische Chemie, Universität-GH-Duisburg, D-47048 Duisburg, Germany

${ }^{\dagger}$ Present address: Department of Chemistry, Cairo University, Giza, Cairo, Egypt

${ }^{\S}$ Present address: Department of Chemistry, University of Esfahan, Esfahan 81744, Iran

\begin{abstract}
Triplet excited 1-acylnaphthalenes add captodative alkenes, especially 2-aminoacrylonitriles, in a formal [4+2] mode to form 1,4-dihydro-1,4-ethanonaphthalenes. This reaction is in some cases preceded by an independent and ultimately less efficient photoreversible 1,2-addition yielding cyclobutanaphthalene derivatives. There is no indication of a common intermediate partitioning into both types of products. Both additions occur with remarkable regio- and stereoselectivity. The chirally labelled alkene $S$ or $R$-2-(2-methoxymethyl-1-pyrrolidinyl)acrylonitrile is added in the [4+2] mode with over $99 \%$ diastereoselectivity leading to practically enantiomerically pure 1,4-adducts. Sensitized cyclodimerizations of 2-morpholinoacrylonitrile are also discussed briefly.
\end{abstract}

Keywords. Photocycloadditions; triplet excited state; 1,4-dihydro-1,4-ethanonaphthaienes; tetrahydrocyclobuta $[a]$ naphthalenes; asymmetric induction.

\section{Introduction}

Photocycloadditions of alkenes to aromatic nuclei continue to be of considerable interest (McCullough 1987). In recent years, numerous novel [4 +2$]$ cycloadditions of so called captodative (Viehe et al 1985) alkenes to carbon atoms 1 and 4 of 1-acylnaphthalenes have been observed (Döpp et al 1985, 1989; Döpp and Memarian 1986, 1990; Memarian 1986; Pies 1989; Mühlbacher 1991). Most recently, novel 1,8-photoadditions of alkenes in a formal [3+2] mode to naphthalene 1,4-dicarboxylates and 1,4-dicarbonitriles have been reported (Kubo et al 1992).

The 1,4-additions to acylnaphthalenes observed by us are of marked regio-, stereo- and diastereoselectivities and are occasionally preceded and/or accompanied by 1,2-additions. Our findings, including hitherto unpublished work, will be summarized and interpreted in the following sections.

\section{Results}

$2 \cdot 1$ 1,4-Ethanonaphthalenes and tetrahydrocyclo-buta[a]naphthalenes from 1-naphthyl carbonyl compounds

Triplet-excited 1-acetonaphthone $(\underline{1 b})$ as well as photoexcited 1-naphthaldehyde (1a) and 1-naphthophenone (1c) form 1,4-photoadducts of type 4 with various

\footnotetext{
* For correspondence
} 
2-aminoacrylonitriles (2) in a highly regio- and stereoselctive manner (Döpp et al 1985; Pies 1989; Döpp and Memarian 1990; Mühlbacher 1991). Without exception, only the benzenoid ring bearing the acyl group is affected. Most investigations have been carried out using 1-acetonaphthone $(1 \mathrm{~b})$ as substrate. Rate constants for quenching of triplet- $1 \mathrm{~b}$ by various type 2 alkenes range from $3 \times 10^{8}$ to $3 \times 10^{9}$ $\mathbf{M}^{-1} \mathbf{s}^{-1}$ in methanol or acetonitrile and are thus smaller than the diffusion controlled limit (Döpp et al 1990).

When we repeated our earlier preparative runs, we found that besides the donor-syn products $4 \mathrm{a}-\mathrm{i}\left(\mathrm{R}=\mathrm{COCH}_{3}\right.$ in most cases), minor amounts of the donor-anti adducts $\underline{5 \mathrm{a}-\mathrm{h}}$ are formed, the syn/anti ratio varying between 95:5 and 89:11 (Mühlbacher 1991).

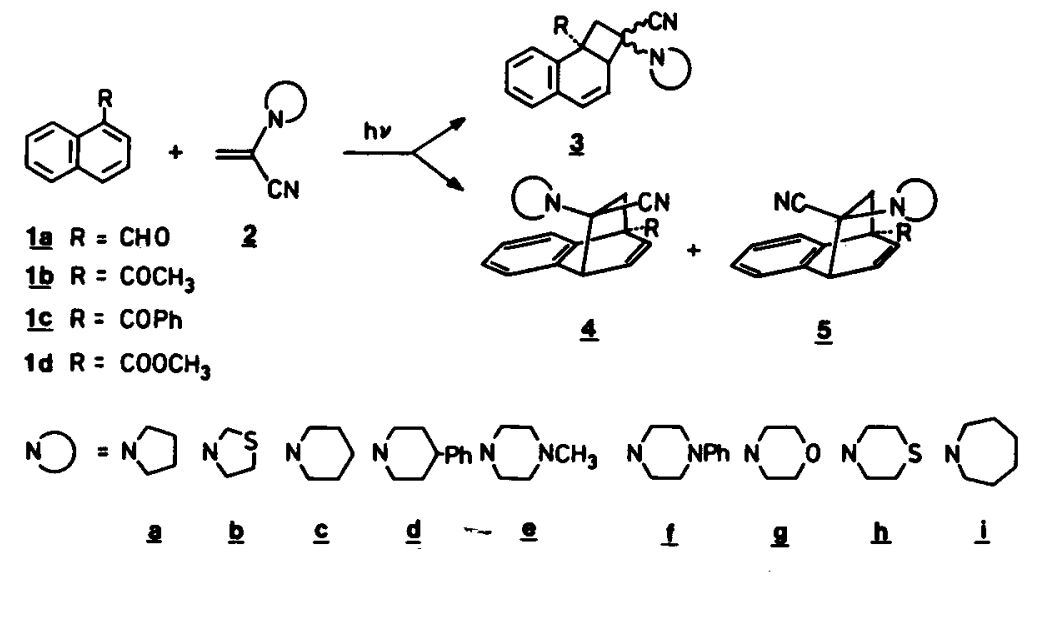

The same trend is observed when methyl-1-naphthoate (1d) is photoexcited in the presence of type 2 olefins (syn/anti varying from 95:5 to 88:12). Thus, the aromatic ester 1d exhibits photochemical behaviour parallel to that of the aromatic ketone $\underline{1 b}$ (Mühlbacher 1991).

Such regio- and stereoselective 1,4-additions to acylnaphthalenes are not restricted to 2-aminoacrylonitriles. Very similar results are obtained with 2-(tert-butylthio) acrylonitrile (Döpp et al 1989). A remarkably high (>99\%) double diastereofacial differentiation leading to practically enantiomerically pure adducts $(+)-$ or $(-)-\underline{4 k}$ can be demonstrated in the [4+2]-photoaddition of either $(S)$ - or $(R)-(2$-methoxymethyl-pyrrolidin-1-yl)acrylonitrile (2k) to 1-acetonaphthone (1b) (Döpp and Pies 1987). The absolute configuration of $(+)-\underline{4 k}$ and $(-)-\underline{4 k}$ (as shown) has been derived from a comparison of ${ }^{1} \mathrm{H}-\mathrm{NMR}$-chemical shifts of $(+)-\underline{4 k}$ with those of analogous 1,4-adducts, in which the donor-syn geometry had clearly been demonstrated by either X-ray structural analysis (Döpp et al 1985, 1989) and/or NOE intensity difference determinations (Mühlbacher 1991), together with the determination of the circular dichroism in the hydrogenated ketone $(+)-\underline{7}$ (Pies 1989). From the positive sign for the Cotton-effect in its $n, \pi^{*}$-absorption the absolute arrangement of the benzenoid ring (formally representing a double bond) and the oxo-group at C-9 (Legrand and Rougier 1977) as depicted is clearly established. Since both the ketones $(-)-\underline{6}$ and $(+)-\underline{6}$ had been demonstrated to be practically free of the respective enantiomers by HPLC using a chiral stationary phase (Döpp and Pies 
1987), $(S)-\underline{2 \mathrm{k}}$ is added solely with its re-face to the si-face of $\underline{1 \mathrm{~b}}$, and $(R)-\underline{2 \mathrm{k}}$ solely with its si-face to re-1b.

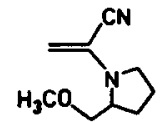

$(\underline{R})-$ or $(\underline{S})-\underline{2 k}$

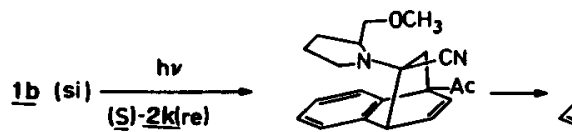

$(+1-\underline{4 k}$

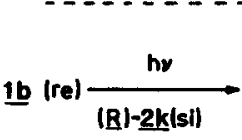

$\mathrm{AC}=\mathrm{COCH}_{3}$
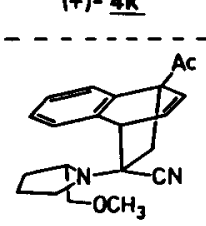

$(-1-\underline{4 k}$

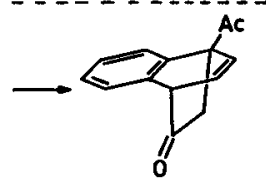

$1+1-6$

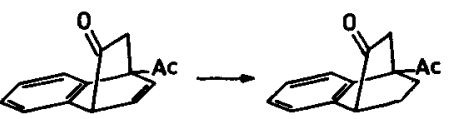

$1+1-\underline{7}$

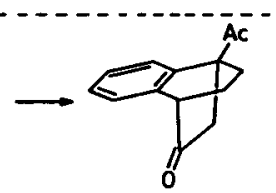

$1-1-\eta$

The origin of the high differentiation observed with $2 \mathrm{k}$ must be sought in the properties of the donor auxiliary and its capabilities for complexation either within a pre-oriented complex of the reactants or within a preferred conformation of a favourable precursor diradical collapsing to $\underline{4 \mathrm{k}}$.

Although temperature-dependency studies, which could cast some light on the relative importance of the precursors mentioned, have not been made yet (and probably will be difficult due to the thermal lability of products of type 4), two levels of selection may be envisaged as outlined in recent pioneering work on the temperaturedependence of asymmetric induction in the Paterno-Büchi reaction (Buschmann et al 1989).

It had been observed earlier (Memarian 1986; Pies 1989), that $2 \mathrm{a}$ and $2 \mathrm{~g}$ also give rise to minor amounts of type $\underline{3}$ adducts of hitherto not clarified configuration at $\mathrm{C}-2$. It could be shown unambiguously that $\underline{2 \mathrm{i}}$ definitely adds to photoexcited $\underline{\mathrm{b}} \mathrm{b}$ to form $\underline{3 i}$ prior to the appearance of $4 \underline{i}$ in the photolysis mixture. Upon prolonged irradiation, however, $\underline{3}$ i is degraded again due to its styrene-like and therefore (compared to $4 \mathrm{i}$ ) conjugated chromophore into starting materials, from which relatively photostable $\underline{4 i}$ is finally formed. Further, since by X-ray single-crystal structure determination the configuration of $\underline{3 i}$ has recently been established to be rel- $(2 S, 2 a S)$, that is with the hexamethyleneimino group anti to the dihydronaphthalene moiety, a direct interconversion of $\underline{3 i}$ into $4 \mathrm{i}$ with least motion of the groups involved is not possible but would require a $180^{\circ}$ torsion around the former cyclobutanaphthalene C-1/C-2 bond.

1,2-and 1,4-Additions selectively to the benzenoid nucleus are observed when common solutions of $\underline{2 g}$ and methyl 8-quinoline carboxylate (8) are irradiated

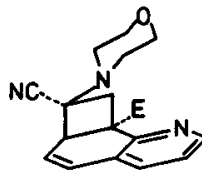

9

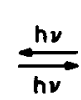<smiles>Cc1cccc(F)c1</smiles>

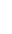<smiles>C=C(C#N)N1CCOCC1</smiles>

$\underline{2 g}$

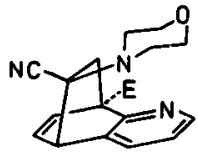

10 
$(>280 \mathrm{~nm}$ ) in benzene or acetonitrile solution (Döpp and Jung 1992). Again, it can be demonstrated that products $\underline{9}$ and $\underline{10}$ emanate from parallel reactions, and that after long irradiation times, $\underline{10}$ is favoured at the expense of 9 .

From this, and the aforementioned case, it may be ruled out that a common intermediate, e.g. the diradical $\mathrm{D}$, connects type $\underline{3}$ and type 4 products. On the other hand, a diradical like $\mathrm{D}$ is an attractive and also logical intermediate in the 1,4-addition, since from spectroscopic (Döpp et al 1990) and quenching studies (Döpp et al 1985; Pies 1989; Mühlbacher 1991), the lowest $\left(\pi, \pi^{*}\right)$ excited triplet state is envisaged as the reactive state in the 1,4-cycloadditions observed. Most logically, this state is followed by a triplet diradical obtained from addition of one molecule of olefin.

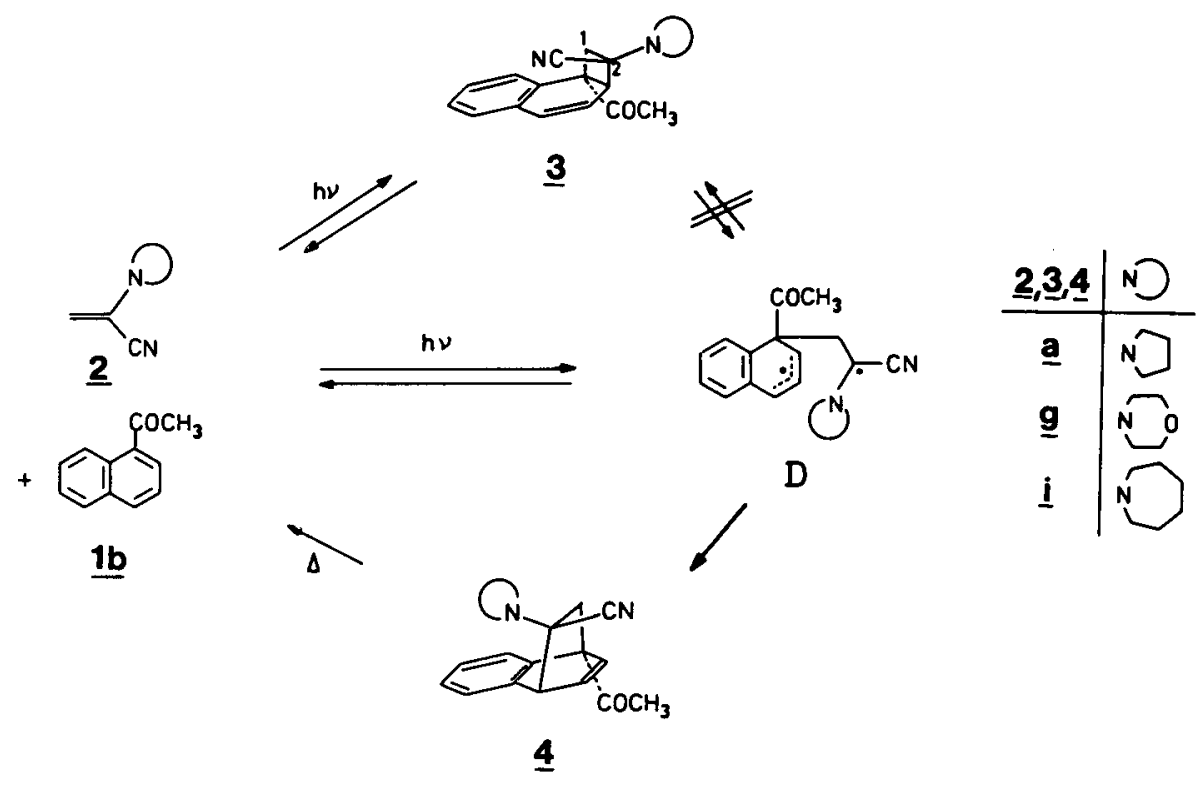

Quantum yields of product formation do not exceed 0.02 , this may reflect low rates of diradical formation and/or efficient fragmentation of unfavourable (extended) conformations of diradicals like D into starting materials (Buschmann et al 1989). It should be stressed, however, that complex-forming orientation of the reactants prior to or after excitation cannot be ruled out at this stage. Neither a ground-state interaction nor an exciplex following the triplet have been detected experimentally, though.

The unique substitution pattern of captodative (Viehe et al 1985) alkenes (one donor and one acceptor group at the same terminus of the double bond) does indeed manifest special features in light-induced cycloadditions. This may also be demonstrated by the comparison of the reactivity of excited 1-acetonaphthone (1b) towards acrylonitrile, 2-(tert-butylthio)acrylonitrile and tert-butyl vinyl sulphide.

Acrylonitrile is not added at all, and, in contrast to the very regio- and stereoselective addition of 2-(tert-butylthio)acrylonitrile giving rise solely to product 11 , tert-butyl vinyl sulphide is added with complete lack of regio- and stereoselectivity to form a mixture of all four a priori possible regio- and stereoisomeric 1,4-dihydro-1,4-ethanonaphthalenes $(\underline{12}, 13)$ (Döpp and Memarian 1986; Lanfermann 


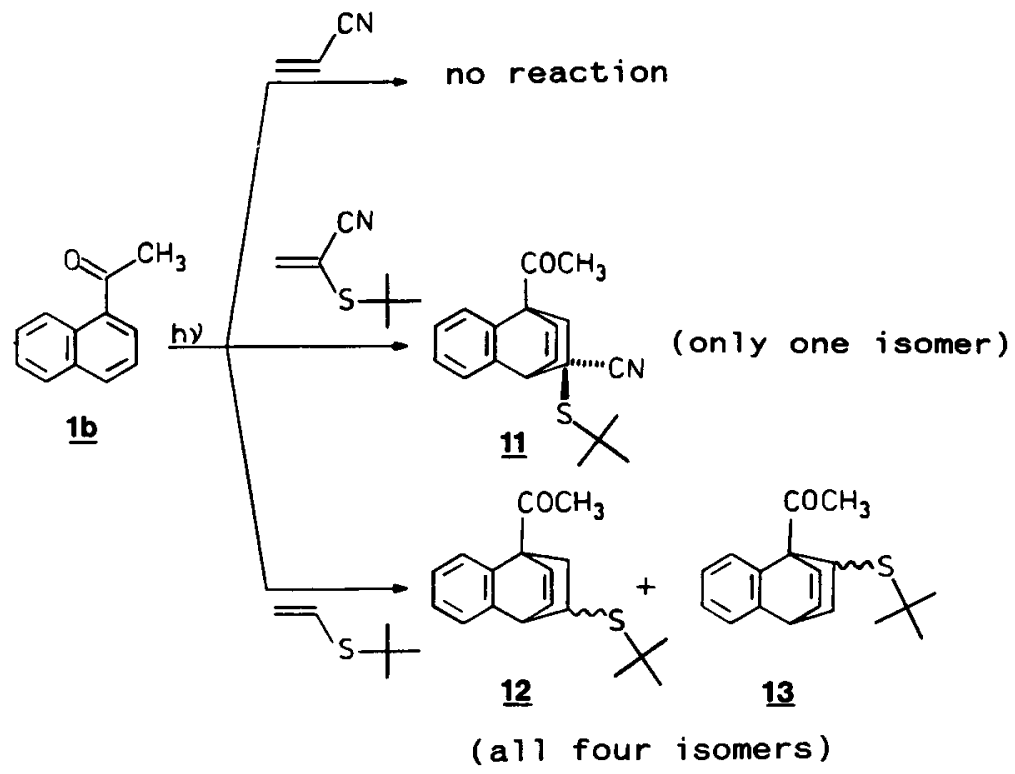

1990). Vinyl ethers, on the other hand, prefer 1,2-addition to $1 \mathrm{~b}, \mathrm{~d}$ (Döpp and Lanfermann 1992), and conventional enamines could not be added in any way to acylnaphthalenes.

It had been tempting to compare the reactivity of excited 1-naphthonitrile (14) with that of the acylnaphthalenes 1a-d towards a representative captodative alkene. Electronically excited $\underline{14}$, probably via its first excited singlet state (McCullough 1987), adds $2 \mathrm{~g}$ with the same direction of addition as observed with $\underline{1 \mathrm{a}-\mathrm{d}}$ to yield 1,2-adducts $\underline{15}$ and $\underline{16}$. In the main product 15 , the syn-orientation of the morpholino group and 1,2-dihydronaphthalene moiety is again derived from an X-ray single crystal structure determination and from NOE intensity difference studies (Döpp et al 1993). Solely NOE results support the syn orientation in by-product $\underline{16}$.<smiles>N#Cc1cccc2ccccc12</smiles>

14

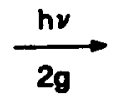

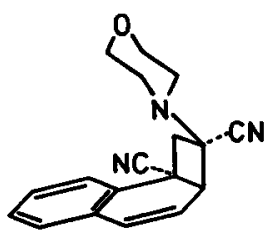

15

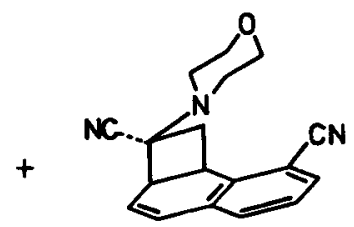

$\underline{16}$

\subsection{Morpholinoacrylonitrile cyclodimerizations}

Whereas 2-alkylthioacrylonitriles tend to dimerize spontaneously (Gundermann and Röhrl 1974), such behaviour is unknown for 2-aminoacrylonitriles.

2-Acetonaphthone and naphthalene-1,8-dicarboxylic acid $\mathrm{N}$-methylimide were found to sensitize, albeit in low yield, the $[2+2]$ head-to-head dimerization of 
2-morpholinoacrylonitrile (2g) (Memarian 1986; Döpp and Bredehorn 1993). The trans structure of the dimer 17 has been confirmed by single-crystal X-ray structural analysis. The role of the sensitizers is still not quite clear, since the photodimerization of $2 \mathrm{~g}$ cannot be driven to yields larger than $12 \%$, whereas the [2+2] dimerization of 2-aminoacrylonitrile, sensitized by benzophenone, has been reported to provide a $75 \%$ yield of both diastereomeric head-to-head dimers (Ksander et al 1987).

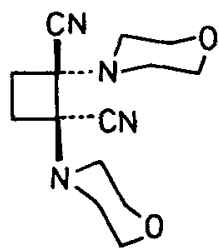

17<smiles>CC1(N2CCOCC2)CCC(C#N)N2CCOCC21</smiles>

18

In addition, both benzophenone and 2-acetonaphthone cause the formation of another cyclodimer from $2 \mathrm{~g}$, to which structure 18 has been assigned on the basis of its $300 \mathrm{MHz}{ }^{1} \mathrm{H}$-NMR-spectrum (Döpp and Bredehorn 1993).

\section{Conclusion}

The highly regio- and stereoselective photoadditions to the naphthalene skeleton, as described here, had not been expected. They add cycloadditions originating from a triplet-excited state to the already rich cycloaddition photochemistry of aromatic compounds starting from excited singlets. Selectivities observed must be attributed at least partly to the unique substitution pattern of captodative alkenes. Since the aminonitrile function at carbon atoms 9 in products of type $\underline{4}$ and 5 and at carbon $\mathbf{2}$ in $\underline{\mathbf{3}}$ may be hydrolysed to give way to an oxo-group, the photoadditions described practically make novel 1,4-dicarbonyl compounds accessible. Thus captodative alkenes function as ketene equivalents in cycloadditions.

\section{Acknowledgements}

The authors are very much indebted to G Henkel, University of Duisburg, for recent unpublished single-crystal X-ray structural determinations and to the late G Snatzke, University of Bochum, for a Cotton-effect determination. Thanks are due to the Deutsche Forschungsgemeinschaft for a fellowship granted to $\mathrm{H}-\mathrm{R}$ Memarian and to the A V Humboldt-Foundation for a fellowship awarded to $\AA \mathrm{W}$ Erian. Generous financial support of this work by the Ministerium für Wissenschaft und Forschung des Landes Nordrhein-Westfalen, by Deutsche Forschungsgemeinschaft and by Fonds der Chemischen Industrie, is gratefully acknowledged.

\section{References}

Buschmann H, Scharf H -D, Hoffmann N, Plath M W and Runsink J 1989 J. Am. Chem. Soc. 1115367 Döpp D and Bredehorn J 1993 (unpublished) (Part of planned doctoral thesis by J Bredehorn, University of Duisburg) 
Döpp D, Erian A W and Henkel G 1993 Chem. Ber. 126239

Döpp D and Jung A 1992 (unpublished) (Part of planned doctoral thesis by A Jung, University of Duisburg)

Döpp D, Krüger C, Memarian H -R and Tsay Y -H 1985 Angew. Chem., Int. Ed. Engl. 241048

Döpp D and Lanfermann H 1992 (unpublished) (Part of planned doctoral thesis by H Lanfermann, University of Duisburg)

Döpp D and Memarian H -R 1986 Substituent effects in radical chemistry (eds) H G Viehe, Z Janousek and R Merenyi (NATO ASI Series, C 189) (Dordrecht: Reidel) p. 383

Döpp D and Memarian H -R 1990 Chem. Ber. 123315

Döpp D, Memarian H -R, Krüger C and Raabe E 1989 Chem. Ber. 122585

Döpp D, Memarian H -R, van Eijk A M J and Varma C A G O 1990 J. Photochem. Photobiol. A53 59

Döpp D and Pies M 1987 J.Chem. Soc., Chem. Commun. 1734

Gundermann K -D and Röhrl E 1974 Lieb. Ann. Chem. 1661

Ksander G, Bold G, Lattmann R, Lehmann C, Früh T, Xiang Y -B, Inomata K, Buser H P, Schreiber J, Zass E and Eschenmoser A 1987 Helv. Chim. Acta 701115

Kubo Y, Inoue T and Sakai H 1992a J. Am. Chem. Soc. 1147660

Kubo Y, Noguchi T and Inoue T 1992b Chem. Lett. 2027

Lanfermann H 1990 Photocycloaddition of tert-butyl vinylsulfide to 1-acetonaphthone, diploma thesis, University of Duisburg

Legrand L M and Rougier M J 1977 Stereochemistry Fundamentals and methods. Vol. 2. Determination of configuration by dipole moments CD or ORD (ed.) H B Kagan (Stuttgart: Thieme) p.33

McCullough J J 1987 Chem. Rev. 87 811, and references cited therein

Memarian H -R 1986 Photoadditions of captodative olefins to acylnaphthalenes, doctoral thesis, University of Duisburg.

Mühlbacher B 1991 Photocycloaddition of captodative olefins to 1-acetonaphthone and methyl 1-naphthoate, doctoral thesis, University of Duisburg

Pies M 1989 Regio-, diastereo- and enantioselectivity in a photo-Diels-Alder-addition, doctoral thesis, University of Duisburg

Viehe H -G, Janousek Z, Merényi R and Stella L 1985 Acc. Chem. Res. 18 148, and references cited therein 